\title{
Expressing TrkC from the TrkA locus causes a subset of dorsal root ganglia neurons to switch fate
}

\author{
Aziz Moqrich ${ }^{1,2}$, Taryn J Earley ${ }^{1}$, James Watson ${ }^{2}$, Mary Andahazy ${ }^{2}$, Carey Backus ${ }^{3}$, Dionisio \\ Martin-Zanca ${ }^{4}$, Douglas E Wright ${ }^{5}$, Louis F Reichardt ${ }^{3}$, and Ardem Patapoutian ${ }^{1,2}$ \\ 1Department of Cell Biology, The Scripps Research Institute, La Jolla, California 92037, USA \\ 2Genomics Institute of the Novartis Research Foundation, San Diego, California 92121, USA \\ 3Program in Neuroscience, Department of Physiology and Howard Hughes Medical Institute, University of \\ California, San Francisco, California 94141, USA \\ 4Instituto de Microbiologia Bioquimica, CSIC/Universidad de Salamanca, 37007, Salamanca, Spain \\ 5University of Kansas Medical Center, Kansas City, Kansas 66160, USA
}

\section{Abstract}

Tactile information is perceived by a heterogeneous population of specialized neurons. Neurotrophin receptors (the receptor tyrosine kinases, Trks) mark the major classes of these sensory neurons: TrkA is expressed in neurons that sense temperature and noxious stimuli, and TrkC is expressed in proprioceptive neurons that sense body position. Neurotrophin signaling through these receptors is required for cell survival. To test whether neurotrophins have an instructive role in sensory specification, we expressed rat TrkC from the TrkA (also known as Ntrkl) locus in mice. The surviving presumptive TrkA-expressing neurons adopted a proprioceptive phenotype, indicating that neurotrophin signaling can specify sensory neuron subtypes.

\begin{abstract}
Neurotrophins are well-characterized growth factors required for the survival of developing sensory neurons by signaling through a class of receptor tyrosine kinases ${ }^{1-3}$. The Trk receptors are specifically expressed in functionally distinct neurons of the dorsal root ganglia (DRG). TrkA, the receptor for nerve growth factor (NGF) is expressed in nociceptive and thermoceptive sensory neurons; TrkC, the high-affinity receptor for neurotrophin-3 (NT-3), is expressed in proprioceptive neurons; and TrkB, the receptor for brain-derived neurotrophic factor (BDNF) and NT-4, is expressed in less specifically characterized touch neurons. Each Trk receptor is required for the survival of the distinct class of neurons that it marks, consistent with a permissive role of neurotrophin signaling in neuronal survival. Various studies have suggested that Trk signaling is also involved in instructive steps of DRG development ${ }^{4}$. For example, neurotrophins are able to guide DRG axons in culture, and $B a x^{--} ; \operatorname{Trk}^{-/-}$or $\mathrm{Bax}^{-/-} ; N^{-1 /-}$ DRG neurons, which are rescued from apoptosis by the lack of functional Bax protein, fail to develop properly ${ }^{5-10}$. To directly test whether signaling by a specific Trk can specify the subtype of DRG neurons in vivo, we designed a knock-in construct that expresses rat TrkC protein from the mouse TrkA locus while inactivating native TrkA expression.
\end{abstract}

(C) 2004 Nature Publishing Group

Correspondence should be addressed to A.P. (E-mail: ardem@scripps.edu)..

COMPETING INTERESTS STATEMENTThe authors declare that they have no competing financial interests. 


\section{RESULTS}

\section{A subset of TrkA-expressing neurons rescued in TrkA ${ }^{\text {TrkC/TrkC }}$ mice}

To address the role of Trks in DRG development without interfering with their role in cell survival, we designed and cloned a transgenic targeting construct that expresses TrkC from the $\operatorname{TrkA}$ genomic locus. In this gene replacement design, we inserted $\operatorname{TrkC}$ (also known as Ntrk3) cDNA preceded by an internal ribosomal entry site (IRES) into the second exon of $\operatorname{TrkA}$ (Fig. 1a,b). This design keeps the $5^{\prime}$ end (first exon and intron) of the TrkA gene intact, ensuring proper mRNA processing. Mice carrying a single allele of $\operatorname{Trk} A^{\operatorname{Trk} C}$ express both the transgene and the endogenous TrkA mRNA in DRGs but not in several other tissues (Fig. 1c). Whereas these heterozygous mice appear normal, animals that carry two copies of the $\operatorname{Trk} A^{T r k C}$ allele do not respond to painful stimuli at birth and die before reaching adult-hood, similarly to $\operatorname{Trk} A$-null mice ${ }^{11}$.

To determine whether expression of TrkC from the TrkA locus rescues any of the DRG neurons

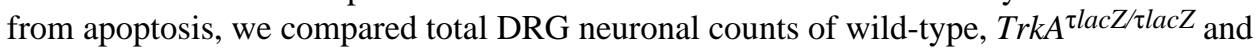

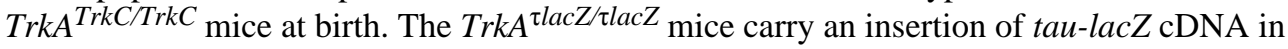
the TrkA locus, and are a phenocopy of TrkA-null mice that lack 70-90\% of sensory neurons (Fig. 2, Table 1 and data not shown) ${ }^{8,11}$. We focused our quantitative analysis on DRGs from the lumbar region (specifically L4 and L5, which contain well-studied ganglia that innervate the hindlimb). As expected, Trk $A^{\text {tlacZ/rlacZ }}$ mice showed a severe reduction in DRG neurons (Table 1). The TrkA ${ }^{\operatorname{Trk} C / T r k C}$ mice also showed a clear deficit in DRGs, but their L5 neuronal

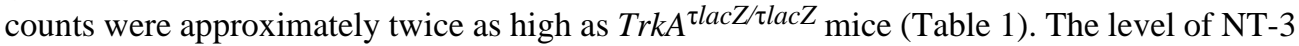
was not manipulated in our experiments, and it presumably limits the number of TrkC neurons that survive in $\operatorname{TrkA} A^{\operatorname{Trk} C / T r k C}$ mice ${ }^{12}$.

\section{The rescued neurons adopt a proprioceptive phenotype}

To characterize the molecular identity of the neurons rescued in the knock-in mice, we monitored the expression of various TrkA- and TrkC-specific genes: Cgrp, which encodes an inflammatory peptide called calcitonin gene-related peptide, Trpvl, which encodes a heat- and capsaicin-activated channel (formerly known as $\operatorname{Vrl}$ ), and $\operatorname{Trpm} 8$, which encodes a cold- and menthol-activated channel. All three are specifically expressed in TrkA-positive DRG neurons in newborn mice ${ }^{13-15}$. The expression of these TrkA-specific genes was not detectable in

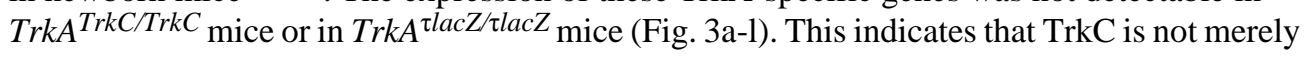
providing a generic survival signal to substitute for TrkA function. Parvalbumin (calciumbinding protein) and ER81 (ETS family transcription factor) are well-characterized markers for TrkC-positive neurons ${ }^{16}$. The expression of these markers in wild-type and

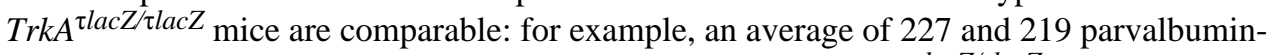
positive neurons are present in the L5 DRGs of wild-type and $\operatorname{Trk} A^{\tau l a c Z / \tau l a c Z}$ mice, respectively (Fig. 3m-u and Table 1). In contrast, the proprioceptive neuron-specific genes (including $\operatorname{Trk} C$ ) are expressed by significantly more neurons in $\operatorname{Trk} A^{T r k C / T r k C}$ mice: for example, nearly three-fold more parvalbumin-positive neurons were observed in L5 DRGs of TrkA ${ }^{\operatorname{TrkC} / T r k C}$ mice than in wild-type mice (Table 1). The increase in proprioceptive-like neurons in $T r k A^{T r k C / T r k C}$ mice was not due to a lack of TrkA neurons, as TrkA $A^{\tau l a c Z / \tau l a c Z}$ mice did not show this phenotype. The additional parvalbumin-positive neurons in L5 DRGs of TrkA ${ }^{T r k C / T r k C}$ mice $(633-219=414)$ fully accounts for the total number of rescued neurons $(857-438=$

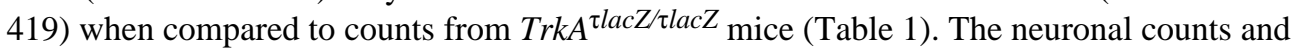
molecular marker analyses suggest that expressing TrkC in place of TrkA results in more neurons that express proprioceptive markers.

In addition to their unique gene expression profiles, TrkA- and TrkC-positive DRG neurons also differ in their anatomical projection patterns ${ }^{3}$. TrkA neurons extend neuronal processes 
to the dorsal spinal cord, whereas TrkC neurons project to the intermediate (Ia and Ib afferents) and ventral spinal cord (Ia afferents). We compared the central projections of DRG neurons using antibodies to CGRP (marking the TrkA population) and parvalbumin (marking the TrkC population). As expected, no CGRP expression was observed in the spinal cord of TrkA $A^{T r k C / T r k C}$ (data not shown). Parvalbumin staining in L5 DRGs is increased in $\operatorname{Trk} A^{T r k C / T r k C}$ mice compared to controls, and most axonal staining in the knock-in mice converge at the intermediate and ventral spinal cord levels-the targets of proprioceptive neurons (Fig. 4a,b). It is difficult to quantify central projections of DRGs, but we were able to analyze peripheral projections in more detail. The peripheral projections of DRG neurons are also unique: TrkA-positive neurons mainly innervate the epidermis and dermis, whereas TrkCpositive neurons project to muscle and tendon tissues. In particular, Ia afferent proprioceptive neurons induce muscle spindles at their termini. Limb muscle spindles do not form in the absence of proprioceptive neurons (as in NT-3-null and $\operatorname{Trk} C$-null mice), but extra muscle spindles are formed in the presence of surplus proprioceptive neurons (as in mice overexpressing NT-3 in muscle) ${ }^{12}$. We counted muscle spindles in hindlimb muscles of wildtype and $\operatorname{Trk} A^{\operatorname{Trk} C / T r k C}$ mice at postnatal day 5 (P5) to assess whether the ectopic TrkC-positive neurons induce proper target tissues. Two- and three-fold increases in the number of muscle spindles were observed in various muscle groups of $\operatorname{Trk} A^{T r k C / T r k C}$ mice (Fig. $4 \mathrm{c}, \mathrm{d}$ and Table 1). Therefore, the ectopic TrkC neurons in $\operatorname{Trk} A^{T r k C / T r k C}$ mice induce and innervate correct proprioceptive-specific targets.

Our results suggest that roughly $8 \%$ of presumptive TrkA-expressing neurons switch to a proprioceptive phenotype upon expression of TrkC, resulting in a 1.5-3 fold increase in this population, and the remaining neurons die. This increase in the number of proprioceptive neurons is similar to the 1.5-2.5 fold increase in proprioceptive neuron numbers observed in myogenin-driven NT3 mice (Myo/NT3) due to the rescue from naturally occurring cell death ${ }^{12}$. To explore whether our phenotype results from the rescue of pre-existing proprioceptive neurons from apoptosis, we created $\operatorname{Trk} A^{\operatorname{Trk} C / T r k C} ; M y o / N T 3$ mice. We reasoned that if expressing TrkC from the TrkA locus prevents cell death of preexisting proprioceptive neurons, then $T r k A^{T r k C / T r k C} ; M y o / N T 3$ mice would show little increase in the number of such neurons compared to Myo/NT3 mice. However, we observed more than an additive increase in proprioceptive neuron counts in $\operatorname{Trk} A^{T r k C / T r k C} ; M y o / N T 3$ mice, including a seven-fold increase of soleus muscle spindles compared to Myo/NT3 mice (and an 11-fold increase compared to wild type; Table 2 and Fig. 4e-h).

To further demonstrate that an effect on survival of existing proprioceptive neurons cannot account for the phenotype observed in $\operatorname{Trk} A^{\operatorname{Trk} C / T r k C}$ mice, we crossed the knock-in mice to $B a x^{-1-}$ mice. The deletion of Bax rescues DRG neurons from apoptosis, but does not cause the formation of extra proprioceptive neurons, as judged by the number of muscle spindles ${ }^{10}$ (also compare parvalbumin and spindle counts in wild-type and $\mathrm{Bax}^{-1-}$ mice; Tables 1 and 2).

Notably, we observed a five-fold increase in parvalbumin-positive L5 DRGs and a seven-fold increase in muscle spindles in the soleus muscle of $\operatorname{Trk} A^{T r k C / T r k C} ; B a x^{-/-}$mice when compared to $\mathrm{Bax}^{-{ }_{-1}}$ mice (Table 2). Since cell death is prevented in both $\operatorname{TrkA}^{\operatorname{TrkC} / T r k C} ; \mathrm{Bax}^{-/-}$and $\mathrm{Bax}^{-/-}$ mice, the increased number of neurons with a proprioceptive phenotype must be the consequence of instructive signals resulting from expression of TrkC at the TrkA locus. Therefore, we have shown that reducing or eliminating neuronal death potentiates the increased proprioceptive phenotype we observe in $\operatorname{Trk} A^{\operatorname{Trk} C / T r k C}$ mice.

\section{Functional endogenous TrkC is required for the phenotypic switch}

In an attempt to visualize the projection patterns of the ectopic proprioceptive neurons, we

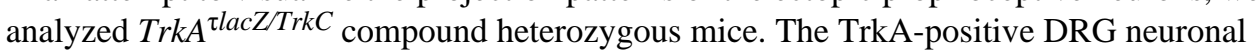
projections are readily visualized by assaying $\beta$-galactosidase activity in mice carrying a single 
copy of $\operatorname{Trk} A^{\text {qlacZ }}$ after embryonic day (E) 13.5 (Figs. 2 and 5a,c). Surprisingly, no $\beta$ galactosidase activity was detected in newborn DRGs of the compound heterozygous mice, similarly to $T r k A^{\tau l a c Z / \tau l a c Z}$ mice (Fig. 5b,d and data not shown). One copy of the TrkC transgene may not be sufficient to rescue neurons from apoptosis. Alternatively, the switch from the nociceptive/thermoceptive to the proprioceptive phenotype may include the eventual downregulation of the TrkA promoter in favor of endogenous TrkC.

The Trk switch hypothesis would predict that the transgene expression in $\operatorname{Trk} A^{\operatorname{TrkC} T r k C}$ mice drives the proprioceptive phenotype by inducing endogenous $\operatorname{Trk} C$. To test this, we generated $\operatorname{Trk} A^{\operatorname{TrkC} / T r k C} ; \operatorname{Trk} C^{-/-}$double-homozygous mice. Although these animals have two copies of the $\operatorname{TrkC}$ transgene, their DRGs do not contain any parvalbumin-positive neurons, similarly to $\operatorname{TrkC}^{-/-}$mice (Fig. 5e-h). Therefore, the phenotype we observed in $\operatorname{Trk} A^{\operatorname{TrkCT} T r k C}$ mice is dependent on the presence of functional endogenous TrkC. Collectively, our data suggests that the mechanism underlying the formation of ectopic proprioceptive neurons in $\operatorname{Trk} A^{\operatorname{Trk} C / T r k C}$ mice is transient expression of the transgene from the TrkA locus that causes a phenotype switch to a proprioceptive neuronal subtype, including a switch in endogenous $T r k$ gene expression (Fig. 5i-k). Is the expression of the transgene transient? RT-PCR analysis with exogenous $\operatorname{TrkC}$-specific primers showed that the transgene is expressed in $\operatorname{Trk} A^{\operatorname{TrkC} / T r k C}$ DRGs at E13.5 but not P7. In contrast, the transgene is expressed in $\operatorname{Trk} A^{T r k C /+}$ mice at both time points (Fig. 51).

\section{DISCUSSION}

Although the neurotrophin knockout phenotypes are consistent with a permissive role for neurotrophins in specific DRG survival, there are many studies that suggest an instructive role for neurotrophins during neuronal development. More than three decades ago, it was shown that injection of NGF can transform immature chromaffin cells into sympathetic neurons in vivo $^{17}$. Neurotrophins have been shown to turn growth cones of sensory axons in vitro ${ }^{5,6,9}$. NT3 is expressed at the tips of extending DRG neurons and its absence results in the loss of these neurons before reaching their final targets 7,18 . Several neurotrophin knock-out mice have shown that loss of Bax function rescues DRG neurons from apoptosis, but the rescued neurons fail to innervate their specific targets $4,8,10$.

We have used transgenic mice to directly examine a potential role of neurotrophins and their receptors in the specification of sensory neuron subtypes. Targeted ectopic expression of TrkC from the $\operatorname{Trk} A$ locus resulted in an increased number of neurons expressing parvalbumin, a marker of proprioceptive neurons. This increase in the proprioceptive population was confirmed by increased density of Ia and Ib afferents in the spinal cord and an increased number of muscle spindles in various muscles. The most parsimonious explanation of our data is that expression of TrkC is sufficient to lead a subset of DRG neurons to a proprioceptive phenotype.

However, only a fraction of the presumptive TrkA-expressing neurons were rescued from cell death. The classical neurotrophic hypothesis proposes that during normal development, sensory neurons are born in excess and nearly half of them die due to competition for limited amounts of neurotrophic factors ${ }^{4}$. Therefore, one could argue that the observed phenotype is actually due to the rescue of the presumptive proprioceptive neurons that normally undergo apoptosis, and not due to a switch in fate. Two lines of evidence argue against this possibility. First, overexpression of NT3 in $T r k A^{T r k C / T r k C}$ led to a larger increase in proprioceptive neuron numbers compared to the combined increases in $T r k A^{T r k C / T r k C}$ or Myo/NT3 mice alone. The six-fold increase in L5 proprioceptive neurons, and 11-fold increase in soleus muscle spindles cannot be readily explained by cell death rescue. A second line of evidence comes from the analysis of $T r k A^{T r k C / T r k C} ; B_{a x}{ }^{-/}$mice. Bax loss of function rescues sensory neurons from naturally occurring cell death. However, this rescue does not result in the formation of extra 
proprioceptive neurons. When we prevented cell death in $\operatorname{Trk} A^{\operatorname{Trk} C / T r k C} ; B a x^{-/-}$mice, we observed a five-fold increase in parvalbumin-positive L5 DRGs and a seven-fold increase of the soleus muscle spindles. This result indicates that the increase in parvalbumin-positive population in the knock-in mice cannot be explained by the effect of TrkC expression on cell survival. Therefore, the increased number of proprioceptive neurons must be due to the ability of TrkC signaling to instruct a proprioceptive fate in DRG neurons.

Still only a fraction of presumptive TrkA-positive neurons switch to a proprioceptive phenotype in $\operatorname{Trk} A^{\text {TrkC/TrkC }} ;$ Bax $^{-/-}$or TrkA ${ }^{\text {TrkCTTrkC }} ;$ Myo/NT3 mice. This suggests that TrkC expression is sufficient to switch neurons to a proprioceptive fate only in a subset of DRG neurons. Why is it that not all presumptive TrkA neurons switch phenotype? First, intrinsic factors within the TrkA population could determine whether a neuron can switch. Second, extrinsic factors within the muscle tissue, for example, could limit the total number of proprioceptive neurons that develop. Third, an inefficient translation of TrkC protein following the IRES sequence in our transgene could limit all presumptive TrkA neurons to switch.

How does TrkC expression lead a DRG neuron to a proprioceptive phenotype? One possibility is that neurotrophins simply act as axon guidance molecules. Neurotrophins are able to turn growth cones of sensory axons in dispersed or organ culture $5,6,9$. The dynamic expression pattern of NT-3 at the tip of growing DRG axons suggests that neurotrophins could potentially guide DRG axons to their destinations in vivo 7,18 . Therefore, TrkC-expressing DRG projections would follow the NT-3 path to correct proprioceptive targets. The targets then induce the terminal phenotype in these neurons. In addition to a role in axonal guidance, intrinsic differences in TrkA and TrkC signaling could directly impact subtype specification. For example, the expression of an individual Trk receptor could regulate (directly or indirectly) a group of transcription factors that impose the correct phenotype on these sensory neurons. Indeed, transcriptional factors Prrx 11, Etv1/Etv4 and Runx3 are expressed in distinct Trkpositive DRG populations, and have been recently shown to be required for various steps of sensory neuron connectivity $19-21$.

Because neuronal survival is a prerequisite to developmental events such as specification and axonal pathfinding, it has been challenging to dissect the role of neurotrophins in these intertwined processes ${ }^{4}$. Here we show that TrkC expression in DRG neurons instructs a proprioceptive phenotype as judged by cellular markers as well as by peripheral and central axonal targeting. Our data imply complex regulatory mechanisms of TrkA and TrkC transcription in developing DRG neurons, and point to the decision to express a particular neurotrophin receptor as a key instructive step in sensory neuron subtype specification.

\section{METHODS}

\section{Generation of the knock-in construct expressing TrkC from the TrkA locus}

The targeting construct was assembled in the plasmid vector pPNTloxPV2 (a gift from J. Yoon and B. Wold, California Institute of Technology). This targeting vector includes positive and negative selection markers: loxP-flanked neomycin (neo flanked by Cre recombinase recognition sequences (loxP sites)) and HSV thymidine kinase genes, both expressed under the PGK promoter. The 5' arm of the targeting vector consists of a $3 \mathrm{~kb}(\mathrm{SmaI}, \mathrm{XhoI})$ fragment of genomic DNA that contains the TrkA intron 1 and the first $40 \mathrm{bp}$ of exon 2. This left arm was fused to a cassette containing an IRES-TrkC cDNA and SV40 poly(A) sequences. IRES and SV40 poly(A) sequences were amplified by PCR from an ETL plasmid (a gift from P. Mombaerts, Rockefeller University). Rat $\operatorname{TrkC}$ cDNA used in this report corresponds to a clone with kinase activity (L14445), and was a gift from P. Tsoulfas (University of Miami School of Medicine) ${ }^{22}$. The $3^{\prime}$ arm of the targeting vector consists of a BamHI-HindIII blunt-ended 1.9-kb fragment containing intron 6 , exon 7 and the first $254 \mathrm{bp}$ of intron 7 . The targeting 
construct was linearized at a unique SmaI site and transfected into the CJ7 embryonic stem (ES) cell line derived from 129S1/SV mice ${ }^{23}$. A homologous recombinant clone was identified by Southern blot analysis of DNA isolated from individual G418/ganciclovir-resistant ES cell colonies. Appropriate integration of the construct was further checked by probes located at the $3^{\prime}$ end of the construct and by sequencing.

\section{Generation and propagation of mice}

To avoid effects of the strong promoter (PGK) on the nearby TrkA regulatory sequences, germline-transmitted $\operatorname{Trk} A^{T r k C} \mathrm{~F} 1$ mice were crossed to $A c t b$-Cre mice (Jackson Laboratories) to delete the selectable marker. The same Cre expressing mice were successfully used for the

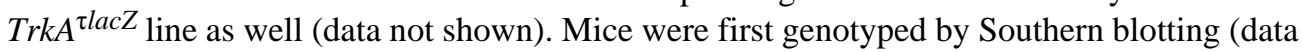
not shown) and then routinely by PCR. TrkA $A^{\text {lacZ/TrkC }}$ compound heterozygous mice were generated by crossing $T r k A^{T r k C /+}$ and $T r k A^{\tau l a c Z /+}$ heterozygous mice. We crossed mice carrying a single allele of both $\operatorname{Trk} A^{T r k C /+}$ and $\operatorname{Trk} C^{+/-}$with $\operatorname{Trk} A^{T r k C /+}$, Myo/NT3, $\operatorname{TrkA}^{\operatorname{TrkCl+}}$ and $\mathrm{Bax}^{+/-}$mice to generate $\operatorname{Trk} A^{\operatorname{TrkC} / T r k C} ; \operatorname{TrkC} \mathrm{C}^{-/-}, \operatorname{Trk} A^{\operatorname{TrkC} / T r k C} ; M y o / N T 3$ and $T r k A^{T r k C / T r k C} ; B a x^{-/-}$offspring. (TrkC-null mice were a generous gift of M. Barbacid, Molecular Oncology Program, Madrid, Spain, and Bax mice were purchased from the Jackson Laboratories).

Primers used: ACheteroexon1F1, 5'-CTAGGCAGTCTGATGACTTCGTT-3'; ACheteroexon1F2, 5'-AGTCTGATGACTTCGTTGATGCT-3'; ACiresR1, 5'GCTACAGACGTTGTTTGTCTTCA-3'; ACiresR2, 5'TTTGACTCTTTCCACAACTATCC-3'; trkTrkAexon3aR, 5'GAGGCCACTCTTCACGATGG-3'; trkTrkAexon3bR, 5'AATGGAAGGCATCAGGGGCC-3'; GAPDHF, 5'ACCCCTTCATTGACCTCAACTACA-3'; GAPDHR, 5'AGTGATGGCATGGACTGTGGTCAT-3'; PER-F, 5'ACTGGAGCGCAAGATTGAGT-3'; PER-R, 5'-CAGCTGTCGAAGCTCTTCCT-3'.

\section{Analysis of $T r k C$ transgene mRNA expression}

Tissues at different time points were assayed for the transgene expression by RT-PCR. Total RNA was extracted using TRIzol LS (Invitrogen/GIBCO Life Technologies) according to the protocol provided by the manufacturer. Approximately $3 \mu \mathrm{g}$ of total RNA was reverse transcribed with reverse transcriptase (Superscript; Gibco-BRL). We used $1 \mu 1$ of cDNA as a PCR template for 30 cycles or fewer.

\section{Total cell counts and parvalbumin-positive neuron counts}

For total cell counts, newborn (P0) mice fixed in Carnoy's solution were embedded in paraffin. For parvalbumin counts, $\mathrm{P} 0$ mice were perfused, fixed in $4 \%$ paraformaldehyde in phosphatebuffered saline (PBS), cryoprotected and then frozen in ethanol/dry ice in OCT mounting medium. Specimens were serially sectioned into $7-\mu \mathrm{m}$ slices and stained with cresyl violet (Nissl) or immunostained with antibody to parvalbumin 6 . Neurons were counted in every fourth section to calculate the total number in each ganglion. Ribs were used as landmarks to identify L4 and L5 DRGs.

\section{Spindle counts}

P5 and P0 legs were separated from skin and fixed overnight in 10\% buffered formalin. The samples were rinsed in running water for $1 \mathrm{~h}$ and microwaved in a decalcification solution containing $8 \%$ hydrochloric acid and $8 \%$ formic acid in water (v/v). A 4-min warm-up step followed by a 45 -min step at $50^{\circ} \mathrm{C}$ completely decalcified the tissues. Samples were rinsed in running water for $1 \mathrm{~h}$ and embedded in paraffin. Transverse sections were cut from the knee 
to the ankle of the hind legs at a thickness of $5 \mu \mathrm{m}$. All sections were stained with hematoxylin and eosin as described and examined with a light microscope ${ }^{24}$. Spindles were identified as encapsulated bundles of small muscle fibers that exhibited accumulations of central nuclei at their equatorial part. Spindle equators were pictured and counted so that no muscle spindle was counted twice.

\section{Statistical analysis}

DRG and muscle spindle counts were compared between corresponding data cells grouped by genotypes using an unpaired Student's $t$-test. Alpha levels of 0.05 were used to determine statistical significance in all tests.

\section{In situ hybridization and immunohistochemistry}

In situ hybridizations and immunohistochemistry was performed as described 15,25 . The ER81 probe was a gift from S. Arber (University of Basel, Switzerland); the parvalbumin probe was directed to nucleotides 80-594 (GenBank accession number NM_013645). The TRPM8 probe was directed to nucleotides 1410-1980 (GenBank accession number AF481480). Immunofluorescence was done with anti-TrkA (1:1,000; gift from L.F. Reichardt, Howard Hughes Medical Institute, University of California, San Francisco), anti-CGRP (1:100; Biogenesis) and anti-parvalbumin (1:2,000; Swant). In experiments using an antibody to TrkC, detection was done with peroxidase-coupled secondary antibodies and the Vectastain ABC kit (Vector Laboratories) ${ }^{6}$.

\section{$\beta$-galactosidase histochemistry}

Detection of $\beta$-galactosidase was done either in whole mount P0 mice or in sections. Whole animal or sections containing DRG neurons were fixed with paraformaldehyde, stained overnight at $37^{\circ} \mathrm{C}$ in X-gal solution containing $5 \mathrm{mM}$ potassium ferrocyanide, $5 \mathrm{mM}$ ferricyanide and $1 \mathrm{mg} / \mathrm{ml} \mathrm{X-gal} \mathrm{in} \mathrm{PBS} \mathrm{(pH} \mathrm{7.5)}+2 \mathrm{mM} \mathrm{MgCl}_{2}$. DRG sections were washed, nuclear fast red stained, dehydrated, cleared and mounted in Permount (Biomeda).

\section{ACKNOWLEDGMENTS}

We thank S. Arber, M. Barbacid, P. Mombaerts, P. Tsoulfas, B. Wold and J. Yoon for reagents; S. Kupriyanov and G. Story for assistance; and S. Halpain, N. Hong, U. Mueller and L. Stowers for critical reading of the manuscript. This work was mainly supported by a National Institute of Neurological Disorders and Stroke grant (5R01NS42822 to A.P.). Other support included: Basil O'Connor Starter Scholar Research Award to A.P., NIH P01-16033 to L.F.R., NIH R29NS37910 to D.E.W., and Spanish Ministry of Science and Technology grant (PM99-0118) to D.M.Z. A.P. is a Damon Runyon Scholar. L.F.R. is an investigator of the Howard Hughes Medical Institute.

\section{References}

1. Scott, SA. Sensory Neurons: Diversity, Development, and Plasticity. Oxford Univ. Press; New York: 1992.

2. Patapoutian A, Reichardt LF. Trk receptors: mediators of neurotrophin action. Curr. Opin. Neurobiol 2001;11:272-280. [PubMed: 11399424]

3. Huang EJ, Reichardt LF. Neurotrophins: roles in neuronal development and function. Annu. Rev. Neurosci 2001;24:677-736. [PubMed: 11520916]

4. Markus A, Patel TD, Snider WD. Neurotrophic factors and axonal growth. Curr. Opin. Neurobiol 2002;12:523-531. [PubMed: 12367631]

5. Gundersen RW, Barrett JN. Neuronal chemotaxis: chick dorsal-root axons turn toward high concentrations of nerve growth factor. Science 1979;206:1079-1080. [PubMed: 493992]

6. Song HJ, Ming GL, Poo MM. cAMP-induced switching in turning direction of nerve growth cones. Nature 1997;388:275-279. [PubMed: 9230436]published erratum appears in Nature389, 412 (1997) 
7. Patapoutian A, Backus C, Kispert A, Reichardt LF. Regulation of neurotrophin-3 expression by epithelial-mesenchymal interactions: the role of Wnt factors. Science 1999;283:1180-1183. [PubMed: 10024246]

8. Patel TD, Jackman A, Rice FL, Kucera J, Snider WD. Development of sensory neurons in the absence of NGF/TrkA signaling in vivo. Neuron 2000;25:345-357. [PubMed: 10719890]

9. Tucker KL, Meyer M, Barde YA. Neurotrophins are required for nerve growth during development. Nat. Neurosci 2001;4:29-37. [PubMed: 11135642]

10. Patel TD, et al. Peripheral NT3 signaling is required for ETS protein expression and central patterning of proprioceptive sensory afferents. Neuron 2003;38:403-416. [PubMed: 12741988]

11. Smeyne RJ, et al. Severe sensory and sympathetic neuropathies in mice carrying a disrupted Trk/NGF receptor gene. Nature 1994;368:246-249. [PubMed: 8145823]

12. Wright DE, Zhou L, Kucera J, Snider WD. Introduction of a neurotrophin-3 transgene into muscle selectively rescues proprioceptive neurons in mice lacking endogenous neurotrophin-3. Neuron 1997;19:503-517. [PubMed: 9331344]

13. Caterina MJ, et al. The capsaicin receptor: a heat-activated ion channel in the pain pathway. Nature 1997;389:816-824. [PubMed: 9349813]see comments

14. McKemy DD, Neuhausser WM, Julius D. Identification of a cold receptor reveals a general role for TRP channels in thermosensation. Nature 2002;416:52-58. [PubMed: 11882888]

15. Peier AM, et al. A TRP channel that senses cold stimuli and menthol. Cell 2002;108:705-715. [PubMed: 11893340]

16. Arber S, Ladle DR, Lin JH, Frank E, Jessell TM. ETS gene Er81 controls the formation of functional connections between group Ia sensory afferents and motor neurons. Cell 2000;101:485-498. [PubMed: 10850491]

17. Aloe L, Levi-Montalcini R. Nerve growth factor-induced transformation of immature chromaffin cells in vivo into sympathetic neurons: effect of antiserum to nerve growth factor. Proc. Natl. Acad. Sci. USA 1979;76:1246-1250. [PubMed: 286308]

18. O'Connor R, Tessier-Lavigne M. Identification of maxillary factor, a maxillary process-derived chemoattractant for developing trigeminal sensory axons. Neuron 1999;24:165-178. [PubMed: 10677035]

19. Chen ZF, et al. The paired homeodomain protein DRG11 is required for the projection of cutaneous sensory afferent fibers to the dorsal spinal cord. Neuron 2001;31:59-73. [PubMed: 11498051]

20. Lin JH, et al. Functionally related motor neuron pool and muscle sensory afferent subtypes defined by coordinate ETS gene expression. Cell 1998;95:393-407. [PubMed: 9814709]

21. Inoue $\mathrm{K}$, et al. Runx 3 controls the axonal projection of proprioceptive dorsal root ganglion neurons. Nat. Neurosci 2002;5:946-954. [PubMed: 12352981]

22. Tsoulfas $\mathrm{P}$, et al. The rat trkC locus encodes multiple neurogenic receptors that exhibit differential response to neurotrophin-3 in PC12 cells. Neuron 1993;10:975-990. [PubMed: 8494648]

23. Swiatek PJ, Gridley T. Perinatal lethality and defects in hindbrain development in mice homozygous for a targeted mutation of the zinc finger gene Krox20. Genes Dev 1993;7:2071-2084. [PubMed: 8224839]

24. Leu M, et al. ErbB2 regulates neuromuscular synapse formation and is essential for muscle spindle development. Development 2003;130:2291-2301. [PubMed: 12702645]

25. Story GM, et al. ANKTM1, a TRP-like channel expressed in nociceptive neurons, is activated by cold temperatures. Cell 2003;112:819-829. [PubMed: 12654248] 


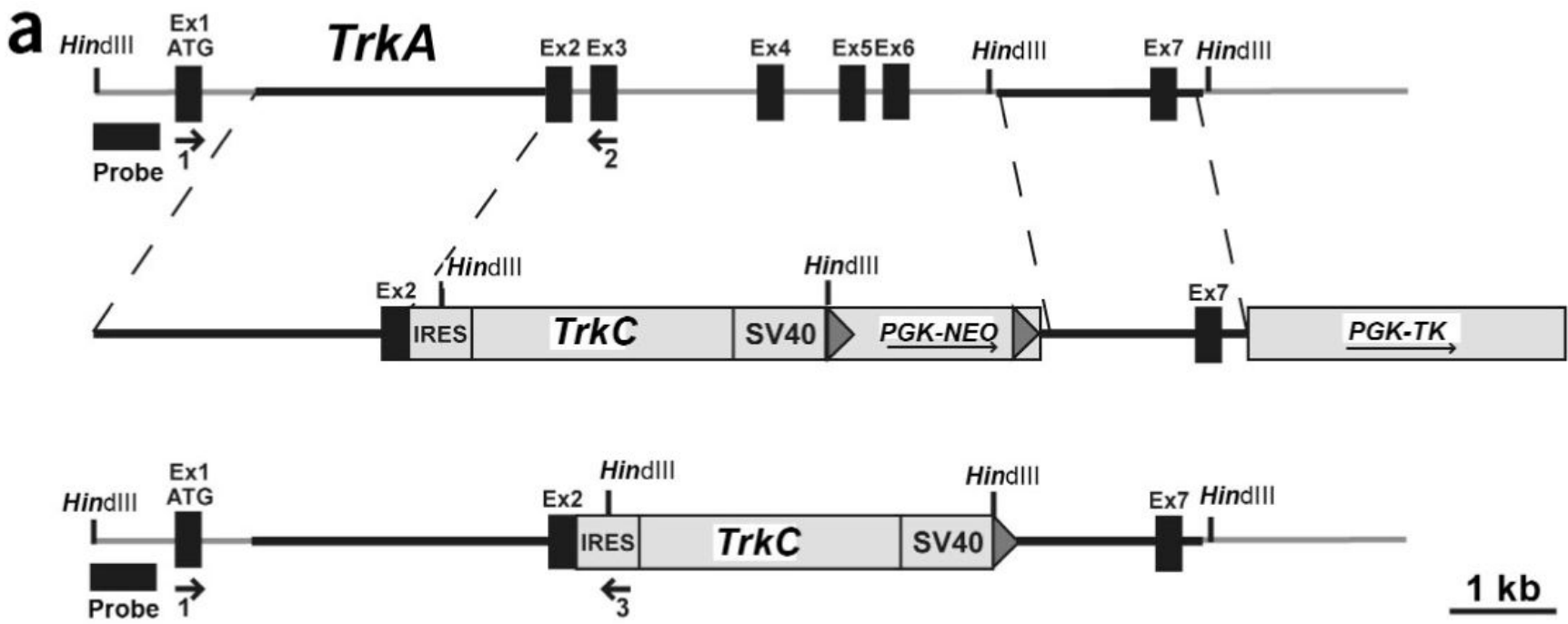

b
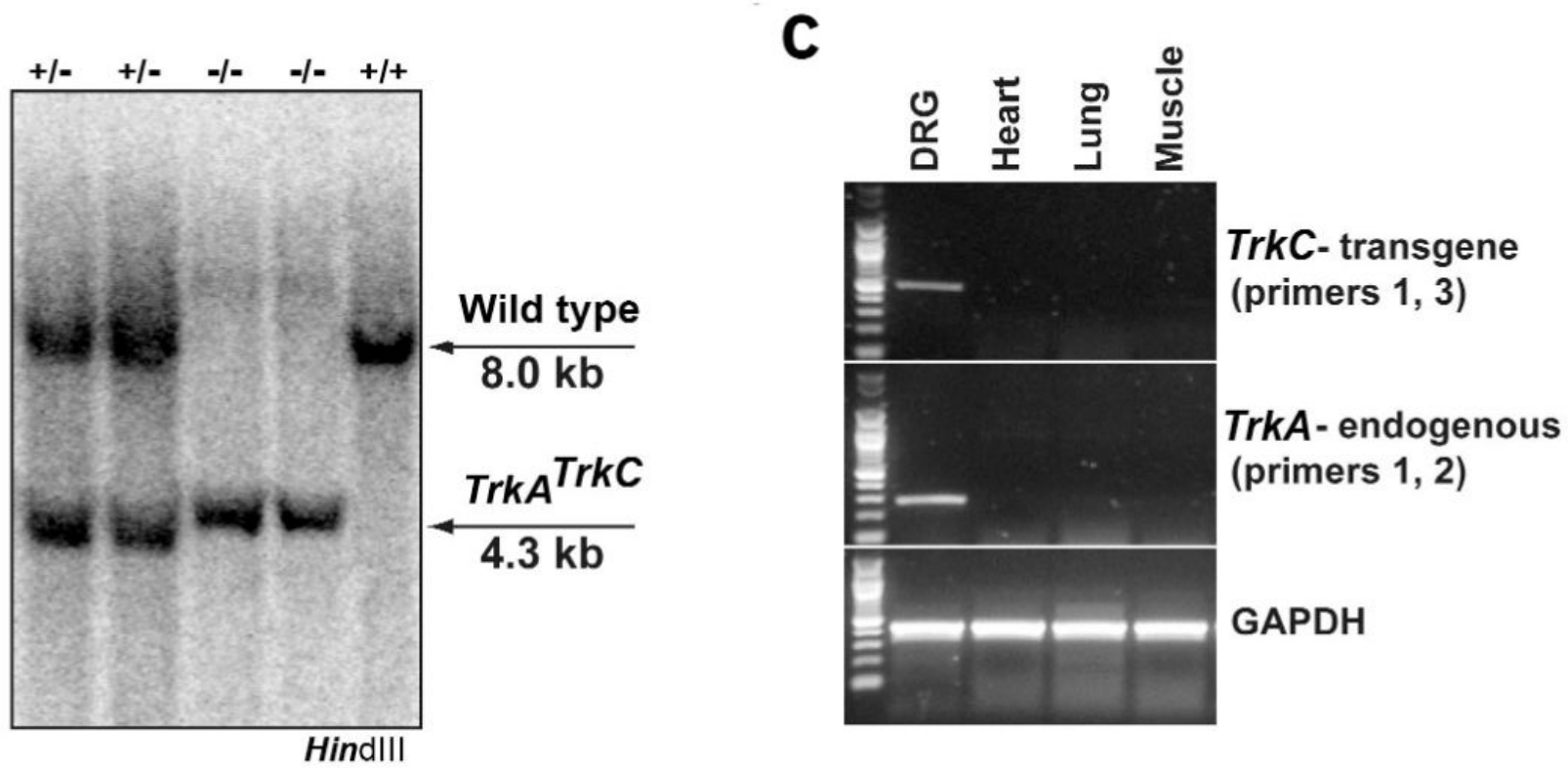

Figure 1.

Mice engineered to express TrkC protein from the TrkA locus. (a) Schematic representation of the TrkA genomic locus, the gene targeting construct and the final $\operatorname{Trk} A^{\operatorname{Tr}} C$ targeted allele. An IRES assures translation of rat TrkC transgenic cDNA independent of the endogenous TrkA start site. The positive selection marker, neo, is flanked by Cre recognition sites (lox $\mathrm{P}$, shown as gray triangles). The removal of the selection cassette ensures proper transcription of the transgene. The locations of HindIII sites, PCR primers and the Southern blot probe are marked. (b) Southern blot analysis of offspring from a $\operatorname{Trk} A^{\operatorname{Tr} C}$ heterozygous intercross. HindIII-digested genomic DNA was hybridized with the $5^{\prime}$ external probe shown in $\mathbf{a}$. The genotype of the mice is shown at the top, where (+) designates a wildtype allele and (-) a $\operatorname{Trk} A^{\text {TrkC }}$ allele. (c) RT-PCR analysis of transgene expression in a $\operatorname{Trk} A^{\operatorname{TrkC}}$ heterozygous mouse. The PCR primers specifically recognized spliced transcripts from either the endogenous $\operatorname{Trk} A$ locus or the $\operatorname{Trk} C$-expressing $\operatorname{Trk} A$ locus. The transgene expression was 
confined to DRG neurons, demonstrating proper tissue-specificity. GAPDH primers were used as a positive control. 

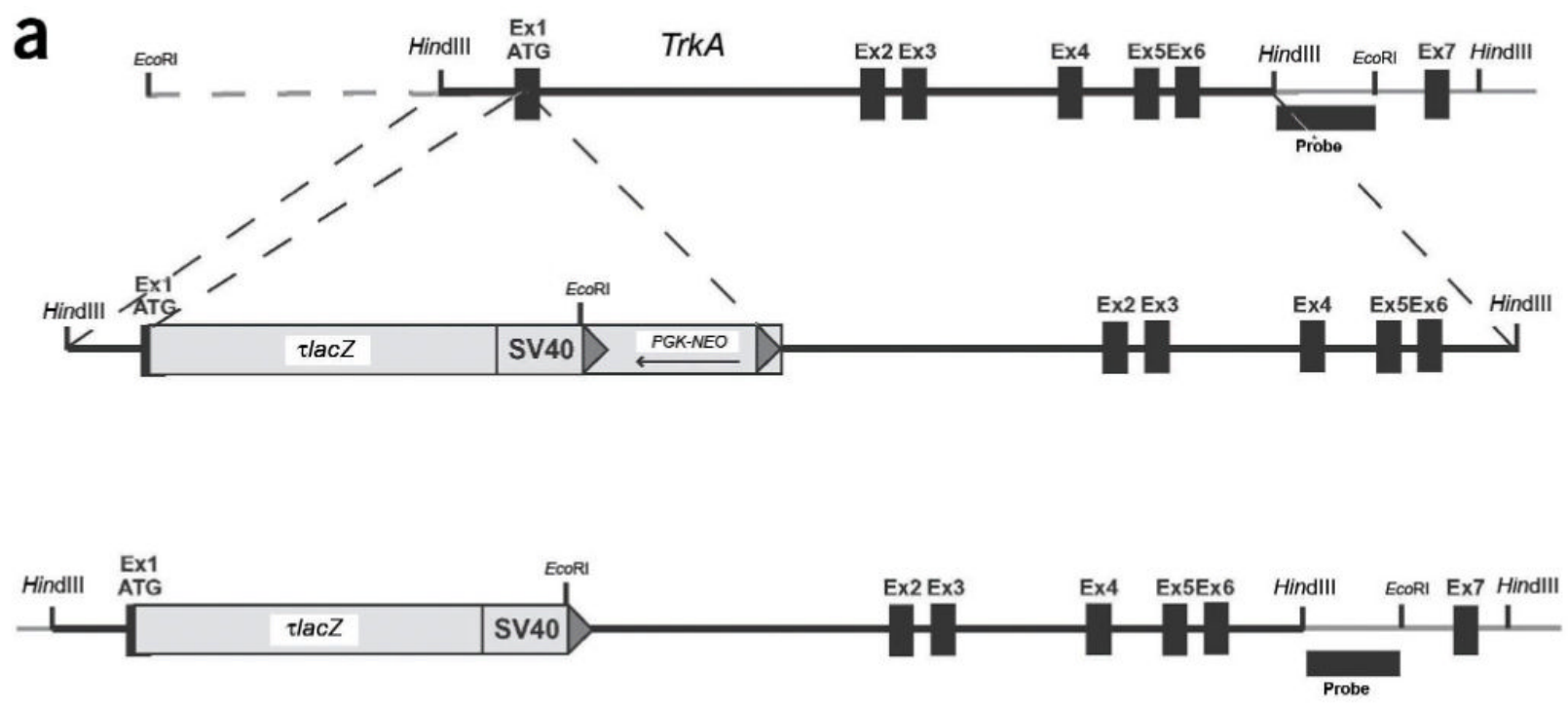

$1 \mathrm{~kb}$

$\mathbf{b}$

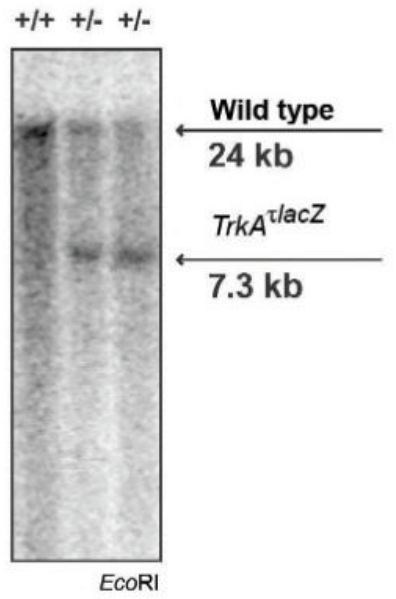

C

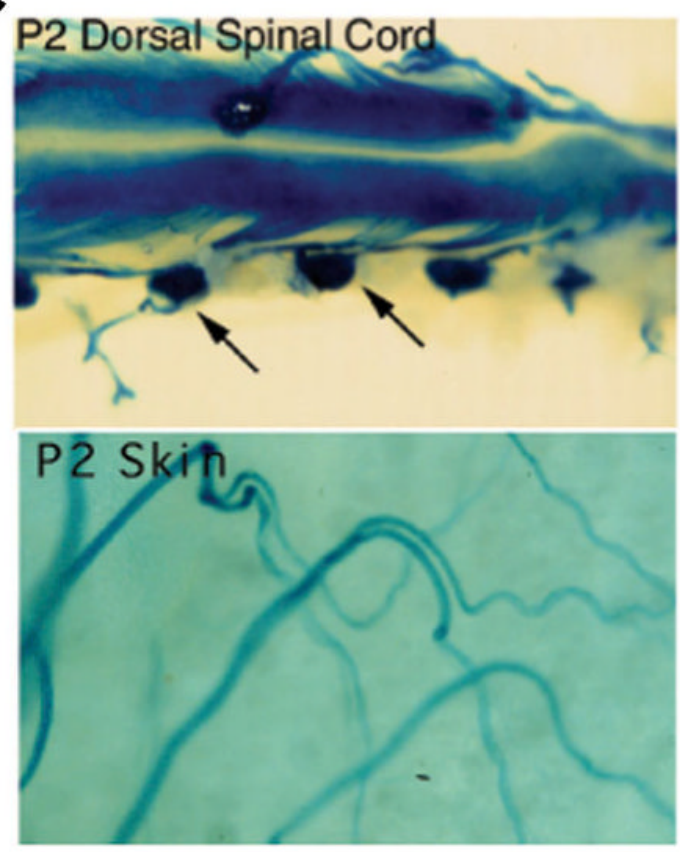

Figure 2.

Mice engineered to express tau-lacZ ( $\tau$ lacZ) fusion protein from the TrkA locus, while inactivating $\operatorname{Trk} A$. (a) Schematic representation of the $\operatorname{Trk} A$ genomic locus, the gene targeting construct and the final TrkA $A^{\tau l a c Z}$ targeted allele. The $\tau$ lacZ-SV40 polyA selection cassette was inserted at the endogenous $\operatorname{Trk} A$ start site (exon 1). The positive selection maker, neo, was flanked by Cre recognition sites (lox $\mathrm{P}$, shown as gray triangles). The removal of the selection cassette ensured proper transcription of the transgene. The locations of HindIII and EcoRI sites and the Southern blot probe are marked. Dashed line in the top diagram indicates that the 5' EcoRI site is not to drawn to scale. (b) Southern blot analysis of $\operatorname{Trk} A^{\tau l a c Z}$ heterozygous mice compared to wild type. EcoRI-digested genomic DNA was hybridized with the $3^{\prime}$ external 
probe shown in a. The genotype of the mice is shown at the top, where (+) designates a wildtype

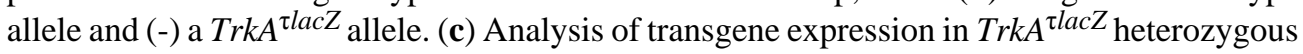
mice using whole-mount $X$-gal staining. At P2, the transgene was expressed in DRG cell bodies (arrows) and TrkA-positive DRG projections in dorsal spinal cord (top) and skin (bottom). Robust expression of transgene was detectable at E13.5. 


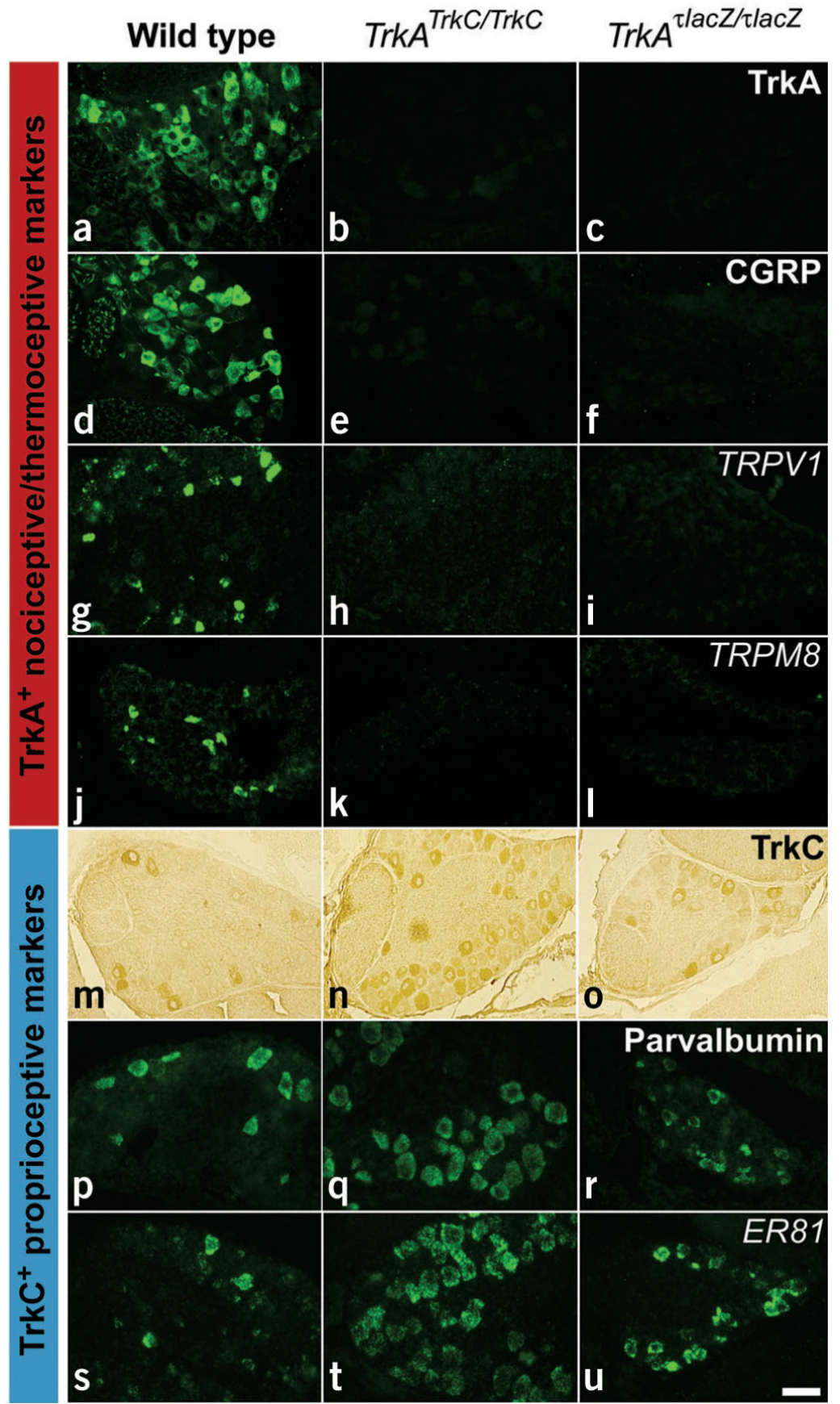

Figure 3.

DRG neurons from $\operatorname{Trk} A^{\operatorname{Trk} C / T r k C}$ mice do not express markers specific for the TrkA population, but a greater number of neurons express markers for the TrkC population. (a-l) Nociceptive-thermoceptive markers were expressed in wild-type DRG neurons $(\mathbf{a}, \mathbf{d}, \mathbf{g}, \mathbf{j})$ but were completely absent in the $\operatorname{Trk} A^{\operatorname{TrkCT} T r k C}(\mathbf{b}, \mathbf{e}, \mathbf{h}, \mathbf{k})$ and $\operatorname{Trk} A^{\tau l a c Z / \tau l a c Z}(\mathbf{c}, \mathbf{f}, \mathbf{i}, \mathbf{I})$ mice at birth. $\operatorname{Trk} A^{\text {tlacZ/rlacZ }}$ mice are phenotypically identical to TrkA-null mice. (m-u) In L5 DRGs, the number of neurons expressing proprioceptive markers were markedly higher in the $\operatorname{Trk} A^{\operatorname{Trk} C / T r k C}$ mice $(\mathbf{n}, \mathbf{q}, \mathbf{t})$ than in wild-type $(\mathbf{m}, \mathbf{p}, \mathbf{s})$ and $\operatorname{Trk} A^{\text {llacZ/rlacZ }}(\mathbf{o}, \mathbf{r}, \mathbf{u})$ mice. The

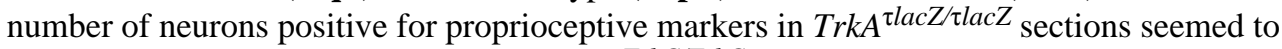
be intermediate between wild type and $\operatorname{Trk} A^{\operatorname{Trk} C / T r k C}$. This apparent increase is likely due to 
the small size of the sensory ganglia, which juxtaposes proprioceptive neurons in close proximity in these sections. Indeed, total counts from wild-type and $\operatorname{Trk} A^{\text {tlacZ/rlacZ }} \mathrm{DRGs}$ show similar numbers of parvalbumin-positive neurons (Table 1). TrkA, CGRP, TrkC and parvalbumin were visualized by antibody staining, and the remaining markers by in situ hybridization. Scale bar is $50 \mu \mathrm{M}$. 

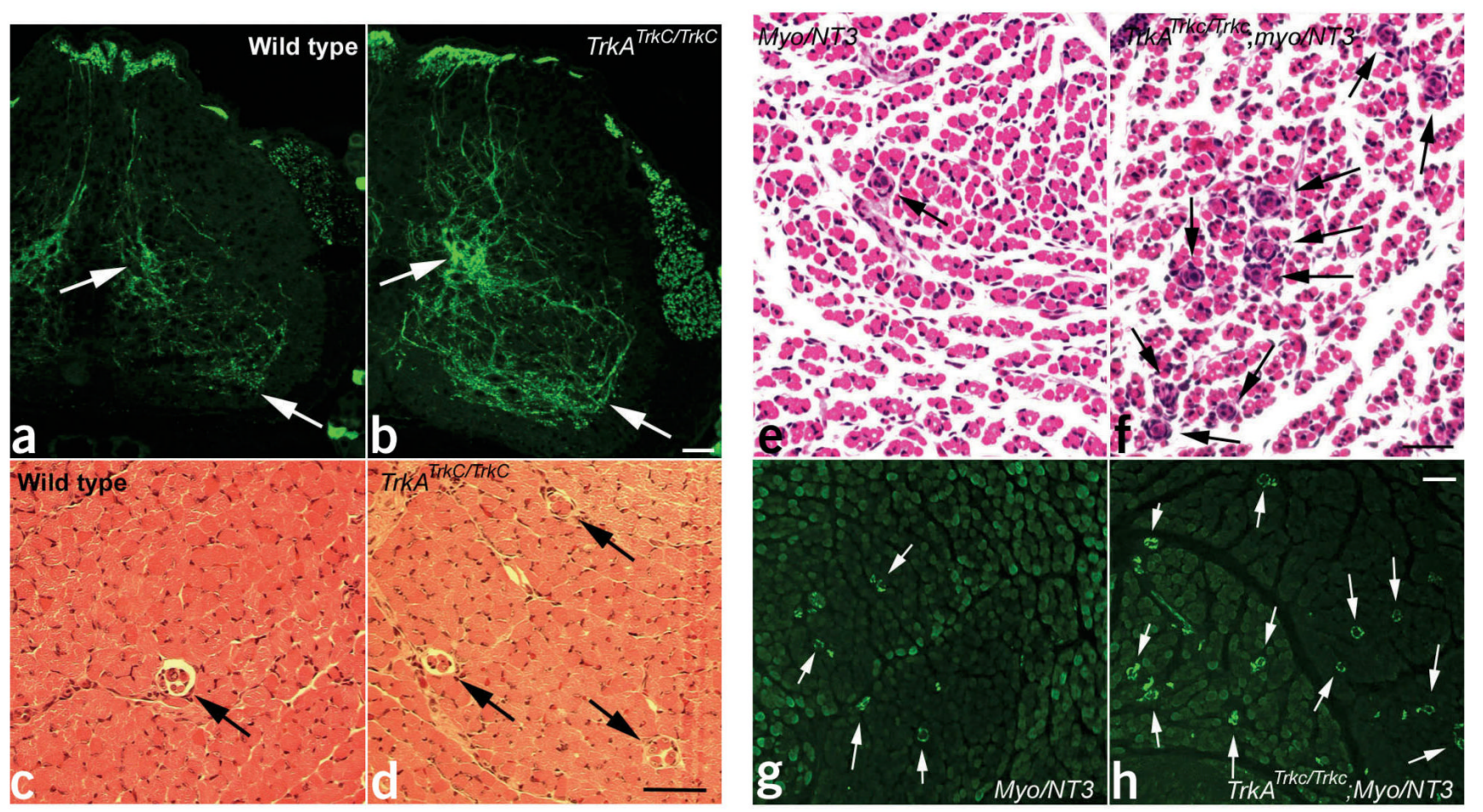

Figure 4.

Increased innervation of proprioceptive target tissues in $\operatorname{Trk} A^{\operatorname{Trk} C / T r k C}$ mice. (a,b) Parvalbumin antibody staining marks the central projections of DRG neurons in wild-type and $T r k A^{T r k C / T r k C}$ mice. The axonal projections converging toward the intermediate and ventral spinal cord (arrows) are denser in the L5 region of TrkA ${ }^{\operatorname{Trk} C / T r k C}$ mice. (c-f) Hematoxylin- and eosin- stained paraffin sections through the soleus muscle show an increased number of spindles (arrows) in the $\operatorname{Trk} A^{\operatorname{TrkCTT} r k C}(\mathbf{d})$ and $\operatorname{Trk} A^{\operatorname{TrkC} T \operatorname{Trk} C} ; M y o / N T 3$ (f) mice at P5 (c,d) and P0 (e,f). (g,h) Parvalbumin-positive muscle spindles within the back muscles at the L5 level of newborn Myo/NT3 (g) and $T r k A^{T r k C / T r k C} ; M y o / N T 3(\mathbf{h})$ mice. Scale bars are $50 \mu \mathrm{M}$. 


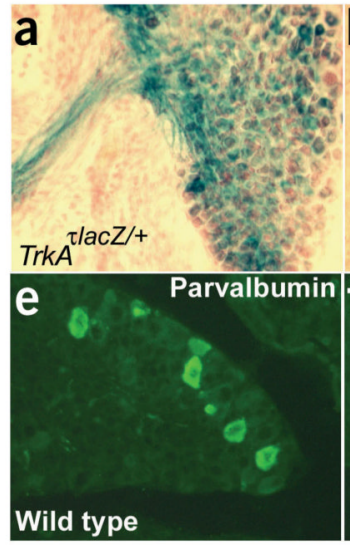

i

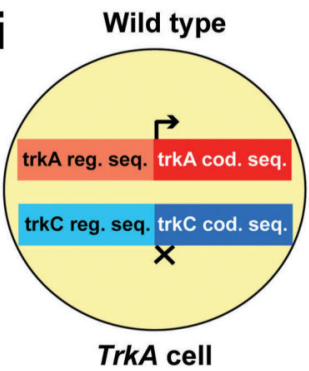

TrkA cell
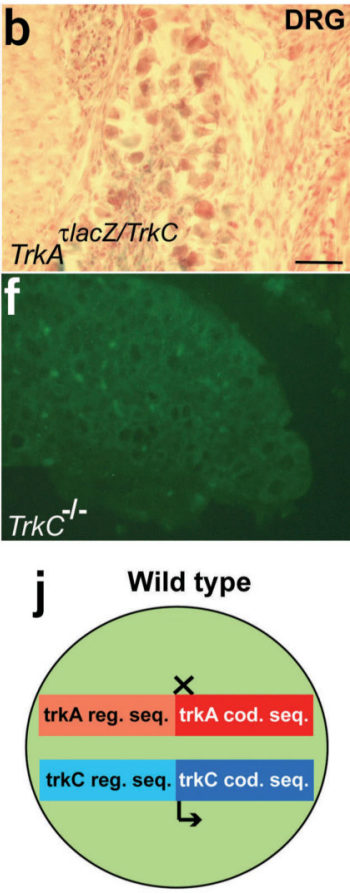

TrkC cell
DRG
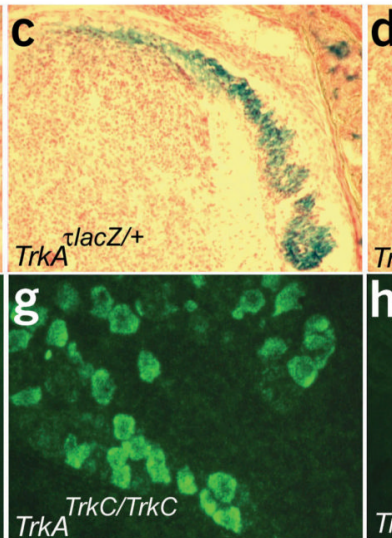

d spinal cord TrkA $A^{\tau l a c Z / T r k C}$
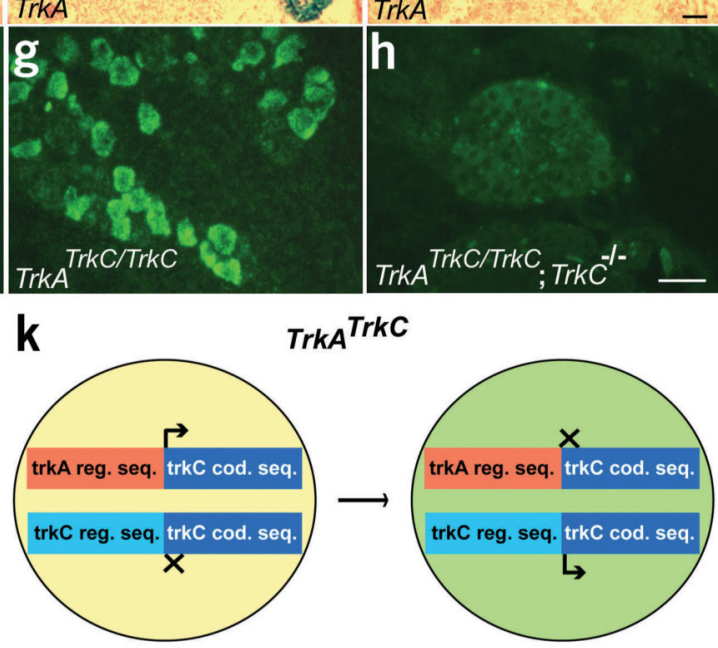

TrkC cell

I

$\begin{array}{lllllllll}E 13 & \text { E13 E13 E13 P7 } & \text { P7 } & \text { P7 } & \text { P7 }\end{array}$ $+/-+/-\quad-/-\quad-/-\quad+/+\quad+/+\quad-/-\quad-/-$

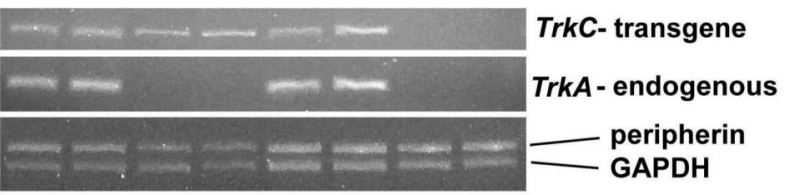

Figure 5.

Mechanism of the phenotypic switch in $\operatorname{Trk} A^{\operatorname{Tr} k C / T r k C}$ mice. (a-d) LacZ-derived activity is apparent in cell bodies (a) and central projections (c) of nociceptive-thermoceptive neurons in

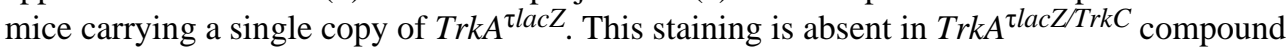
heterozygous mice (b,d). (e-h) In situ hybridization analysis shows that DRG neurons from $\operatorname{TrkA} A^{\operatorname{TrkC} T r k C} ; \operatorname{TrkC}^{-/-}$double homozygous mice do not express the proprioceptive marker parvalbumin (h), similarly to $\operatorname{Trk} C^{-/-}$mice (f), indicating that endogenous $\operatorname{Tr} C C$ is required for the phenotype observed in $\operatorname{Trk} A^{\operatorname{Tr} k C / \operatorname{Tr} C}$ mice (g). (i-k) A model of the mechanism underlying the phenotypic switch described in this study. Neurons in $\operatorname{Trk} A^{\operatorname{Tr} K C / T r k C}$ mice that initially activate the $\operatorname{Trk} A$ promoter now instead express $\operatorname{Trk} C$. This leads to a Trk switch, including the downregulation of the $\operatorname{TrkA}$ promoter and upregulation of the endogenous $\operatorname{Trk} C$ promoter. (l) Levels of $\operatorname{TrkC}$ transgene expression were assessed by semiquantitative RT-PCR at two different time points. GAPDH and peripherin transcripts were used as controls for the cDNA samples. Consistent results were obtained in three different experiments. In agreement with the above model, the transgene was expressed at E13.5 in both $\operatorname{Trk} A^{\operatorname{TrkC}}$ and $\operatorname{Trk} A^{\operatorname{Trk} C / \operatorname{TrkC}}$ mice. Postnatally, the transgene was expressed in heterozygous, but not homozygous, mice. $\operatorname{Trk} A$ was absent in all homozygous samples, as expected. 


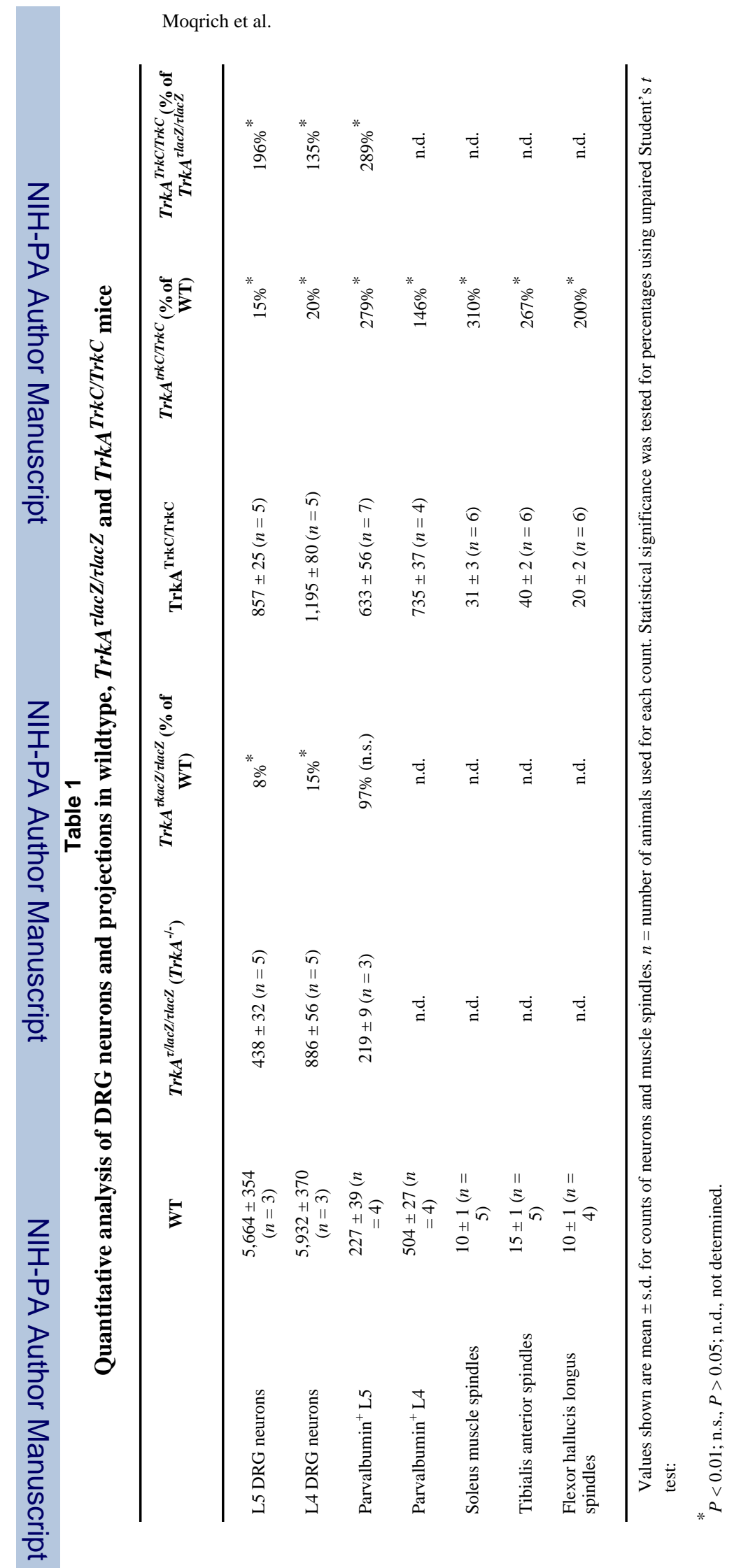

Nat Neurosci. Author manuscript; available in PMC 2009 June 8. 


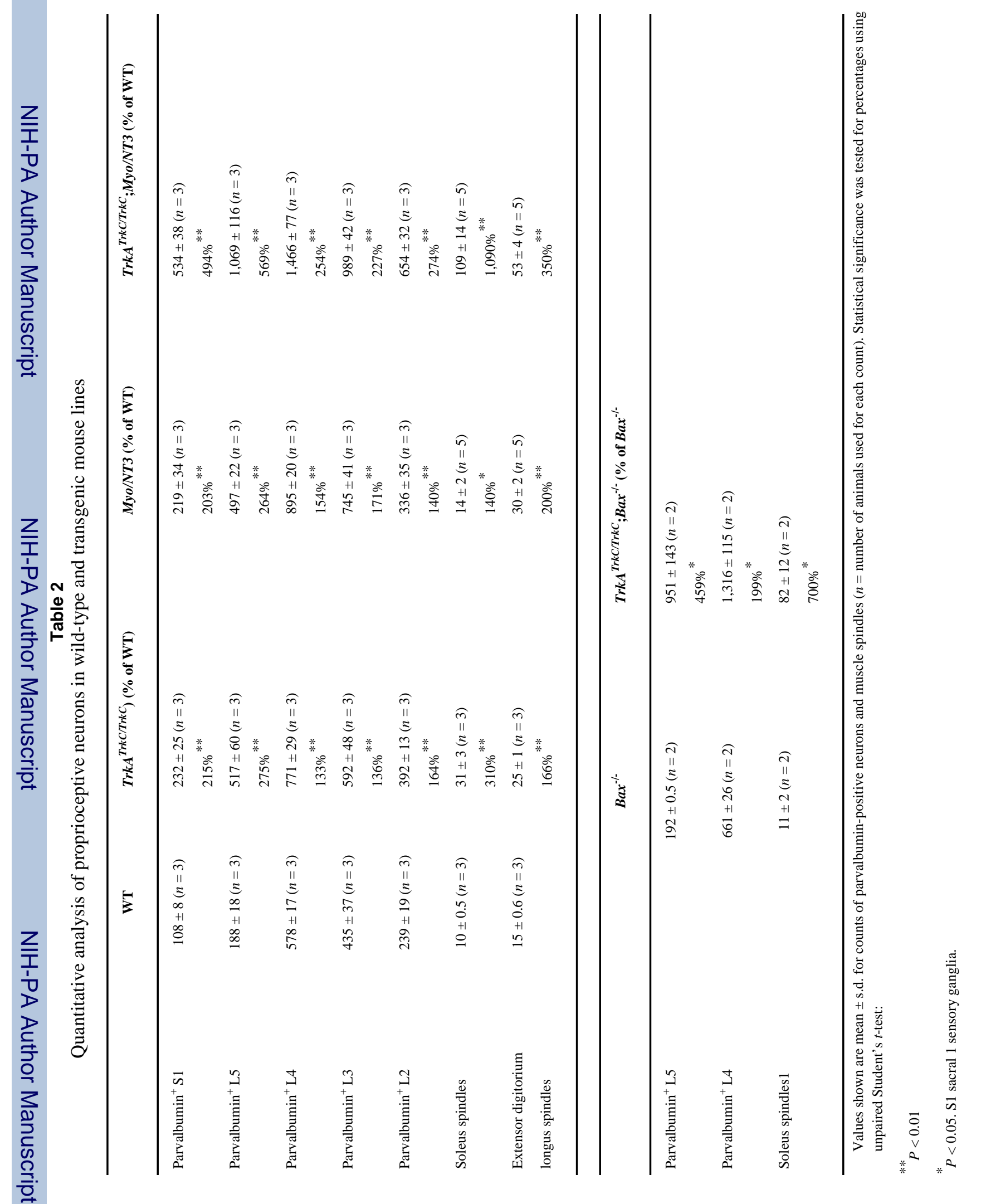

